\title{
Evaluation of Reinfection in COVID-19 Patients in the World: A Narrative Review
}

\author{
Babak Eshrati ${ }^{1}$, Hamid Reza Baradaran ${ }^{2,3}$, Ghobad Moradi ${ }^{4}$, Hojat Dehghanbanadaki ${ }^{5}$, Nima Azh ${ }^{6}$, Marzieh Soheili ${ }^{7}$ \\ Nogol Moetamed Gorji ${ }^{6}$, Yousef Moradi ${ }^{4} *$ (1)
}

Received: 31 Mar 2021

Published: 1 Nov 2021

\section{Abstract}

Background: The evaluation of reinfection and the genetic structure of all human and virus genomes could help to develop programs and protocols for providing services and ultimately to prevent the disease by producing more effective vaccines. Therefore, the aim of this study was to investigate the presence and occurrence of COVID-19 reinfection through a narrative review study.

Methods: We searched the Medline (PubMed), Embase, Scopus, Web of Science, Cochrane library, Ovid, and CINHAL databases. Inclusion criteria included all studies whose main purpose was to provide information about the occurrence or presence of reinfection in patients with COVID-19. An independent samples t test was used to compare the continuous outcomes between the 2 groups.

Results: The mean duration of the first episode in the group with mild or moderate COVID-19 was $24.42 \pm 1.67$ days, and it was $21.80 \pm 3.79$ days in the group with severe COVID-19. The mean duration of the second episode (reinfection) in patients with mild or moderate form was $15.38 \pm 5.57$ days, and it was 19.20 \pm 2.98 days in patients with severe form. In both episodes, the duration of the disease did not significantly differ between the 2 groups ( $p=0.484$ in the first episode; $p=0.675$ in the second episode), but the interval to the occurrence of reinfection in patients with the mild or moderate form was significantly longer than those with the severe form $(\mathrm{p}<0.001)$. In this instance, the time interval in patients with the mild or moderate form was $36.63 \pm 5.71$ days while in those with the severe form of the disease it was $29.70 \pm 5.65$ days. Besides, the genomes of the viruses isolated from the first and second episode were different.

Conclusion: According to the results, all patients should be very careful about the severity of the second episode because of the more need for medical interventions for saving the patients. The interval between the first end and the: second episode as well as the duration of each episode is highly important for better management of the disease.

Keywords: Reinfection, COVID-19, Narrative Review

Conflicts of Interest: None declared

Funding: None

*This work has been published under CC BY-NC-SA 1.0 license.

Copyright $\subseteq$ Iran University of Medical Sciences

Cite this article as: Eshrati B, Baradaran HR, Moradi G, Dehghanbanadaki H, Azh N, Soheili M, Moetamed Gorji N, Moradi Y. Evaluation of Reinfection in COVID-19 Patients in the World: A Narrative Review. Med J Islam Repub Iran. 2021 (1 Nov);35:144. https://doi.org/10.47176/mjiri.35.144

\section{Introduction}

The spread of COVID-19 was unique because of its high transmission rate, causing an emergency in global health in less than a few months around the world (1).

Corresponding author: Dr Yousef Moradi, yousefmoradi211@yahoo.com

1. Preventive Medicine and Public Health Research Center, Iran University of Medical Sciences, Tehran, Iran

2. Ageing Clinical \& Experimental Research Team, Institute of Applied Health Sciences, University of Aberdeen, UK

3. Department of Epidemiology, School of Public Health, Iran University of Medical Sciences, Tehran, Iran

4. Social Determinants of Health Research Center, Research Institute for Health Development, Kurdistan University of Medical Sciences, Sanandaj, Iran

5. Students Scientific Research Center, Tehran University of Medical Sciences, Tehran, Iran

6. Faculty of Medicine, Iran University of Medical Sciences, Tehran, Iran

7. Faculty of Medicine, Kermanshah University of Medical Sciences, Kermanshah, Iran
When the number of cases an d deaths increased, the number of requests and referrals to health care services would increase and the service provision to different

$\uparrow$ What is "already known” in this topic:

The evaluation of reinfection and the genetic structure of all human and virus genomes could help to develop programs and protocols for providing services and ultimately to prevent the disease by producing more effective vaccines.

\section{$\rightarrow$ What this article adds:}

All patients should be very careful about the severity of the second episode because of the more need for medical interventions for saving the patients. 
groups of society became difficult $(2,3)$.

Therefore, in addition to the major problems and obstacles in manufacturing and accessing vaccines, acquired immunity due to natural infection was also very controversial. Many studies in the world on the safety of the disease reached a final summation, but the first case of reinfection in a 33-year-old Hong Kong man created the suspicion that immunity from the disease may not be too long, and the recovered people who were discharged from medical centers would be reinfected (4-6). The evaluation of reinfection and the genetic structure of all human and virus genomes could help to develop programs and protocols for providing services and ultimately to prevent the disease by producing more effective vaccines. Therefore, the aim of this study was to investigate the presence and occurrence of COVID-19 reinfection through a rapid review approach.

\section{Methods}

This study was designed as a narrative review and was conducted in 4 basic steps, including information sources and literature search, screening and selecting articles, data extraction, and qualitative and quantitative analysis of the results (7-9). The review was not registered in PROSPERO and corresponding authors were not contacted due to time constraints.

\section{Information Sources and Literature Search}

In this study, first, keywords related to the subject, such as COVID-19 and reinfection, were identified, and then the synonyms of these keywords were extracted from $\mathrm{MeSH}$ and Emtree databases and related articles. In the next step, these keywords were placed next to each other, and in accordance with each search database, the search strategy and syntax were developed. The desired databases included PubMed, Scopus, Medline, Embase, and Web of Science. To perform gray literature, related sites such as those of the World Health Organization (https://www.who.int/emergencies/diseases/novel-

coronavirus-2019), Centers for Disease Control and Prevention (https://www.who.int/emergencies/diseases/novelcoronavirus-2019), European Centre for Disease Prevention and Control (https://www.ecdc.europa.eu /en/geographical-distribution-2019-ncov-cases), and medRxiv.org, and the preprint server for Health Sciences were searched. The mentioned databases were explored up to November 20,2020. The search strategy was independently conducted by 2 authors and disputes were referred to a third author. Inclusion criteria contained all studies whose main purpose was to provide information on the occurrence or presence of reinfection in patients with COVID-19.

\section{Screening Process}

After searching, the results were entered into version 8 of the endnote software. Then, the papers were screened based on titles, abstracts, and full-texts. The screening was independently conducted by the 2 authors and the disputes were referred to the third author.

\section{Data Items and Data Abstraction Process}

Data extraction in this study was performed through a checklist designed according to the recommendations of study experts and specialists. The checklist included questions such as authors' names, year of publication, country, type of study, main findings, and comments on the study. In addition, the clinical signs and symptoms in each study were extracted and analyzed separately.

\section{Synthesis}

To combine the results of the studies, a review through the qualitative strategy was applied. The method of analysis was performed by the 2 authors as a content analysis. For quantitative analysis, patients were divided into mild or moderate group and severe group based on the severity of the second episode of the disease. An independent t test was used to compare the continuous outcomes between the 2 groups. The outcomes, including the duration of disease in each episode and the time interval between the 2 episodes were presented as mean \pm SE. The significant level was set as $p<0.05$. All statistical analyses were executed in STATA Version 16 (StataCorp).

\section{Results}

After screening, 3248 articles were retrieved from different international databases. A total of 3002 articles were excluded based on their titles and abstracts. Thus, 227 articles were evaluated based on their full-texts and, finally, 20 articles were entered into the final qualitative and quantitative analysis (Fig.. 1). Of all the articles included in the present study, 14 were case reports $(5,10$ $22), 2$ case series $(23,24), 3$ original studies $(25,26)$, and 1 was a letter to the editor (27). Six studies had been conducted in European countries (the Netherlands, Italy, Belgium, and France), 6 in China, 5 in the United States, 1 in Hong Kong, 1 in Brazil, and 1 in India (Table 1).

The findings of this rapid review showed that people with COVID-19, after a periodl of treatment and recovery, could be reinfected. According to previous studies, the virus could not reappear in vitro $(21,27)$. This result led to the hypothesis that it could not reappear in the human body too, but the results of several case studies indicating the presence of reinfection in recovered patients were entered into this review. Immunoglobulin M (IgM) levels were very high in the first 2 weeks of the disease, indicating an acute infection, and after 1 week, IgG levels increased, representing the presence of antibodies and a history of infection. High IgG levels in the body could be demonstrative of high immunity in people. By reducing its levels over time, it could be concluded that the person became susceptible to reinfection $(21,27)$ (Table 1$)$.

Epidemiological, clinical, serological, and genomic analyses in many case studies included in this review confirmed that the patient would be infected again, instead of the continuous reduction and loss of virus load from the first infection $(28,29)$. SARS-CoV-2 may be reactivated and circulated between humans despite the acquired immunity due to infection, which made the disease appear after a while $(22,30)$.

Confirming these results required further studies and 


\section{$\mathrm{N}=3248$ (Medline, PubMed, Embase, Scopus, Manual Search and Gray Literature)}

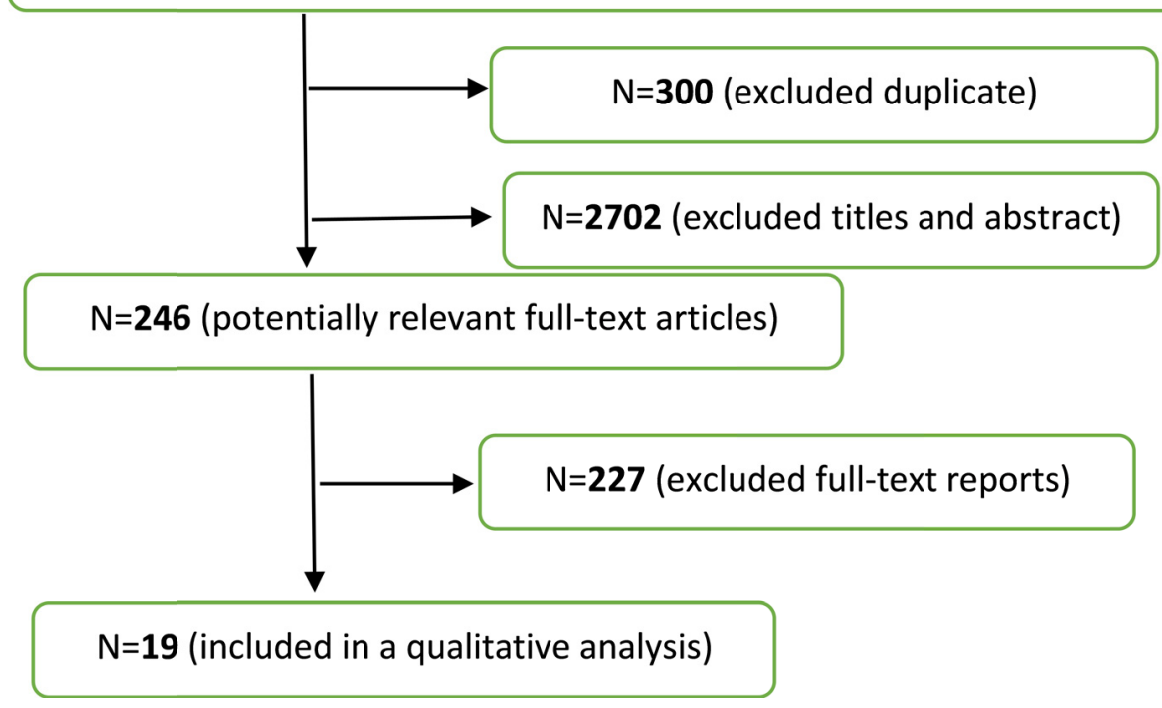

Fig. 1. Study Flow Diagram

genome analyses of COVID-19 affecting people in order to develop more detailed plans for vaccine preparation and immunity of the medical staff. On the other hand, another reason for the need for the evaluation of the genome of the virus and people with COVID-19 was that the polymerase chain reaction (PCR) could stay positive for up to 104 days, and after this period, it was possible to be infected again, but it could not be diagnosed by the available tests. Also, many tests did not have an appropriate diagnostic performance and could not recognize it even if there was a virus in the body $(10,31)$ (Table 1$)$.

The results showed that asymptomatic and mild cases usually had more RNA loss than severe cases. Therefore, it could be concluded that mild and asymptomatic cases were more susceptible to be reinfected with more severe symptoms $(13,14)$. Several studies were conducted among medical staff, indicating reinfection in these patients. These people were more likely to be reinfected because of dealing with different groups of society and different types of patients with COVID-19. On the other hand, the elderly compared with the other age groups were very sensitive to the reinfection. These people had more severe symptoms and even death because of taking different medications and chronic diseases. The results of some case studies expressed that in the case of reinfection, the severity and frequency of symptoms would be much higher than those of the first episode $(6,12,14,17,18,22,30$, $32,33)$. In most case studies on the occurrence of reinfection, the evaluated cases were mostly women, which made the hypothesis that women were more likely to develop reinfection than men $(6,12,14,17,18,22,30,32,33)$ (Table 1).

A case study conducted on a patient with lupus who had COVID-19 showed that after treatment, a complete recovery was observed following various symptoms and tests; however, after a while, the patient was diagnosed with COVID-19 again. The results of this case study indicated that because of taking different types of drugs for treating the underlying disease, the immune system had been weakened, which caused the increased risk of reinfection in these populations (34) (Table 1).

Reinfection was identified in many studies based on SARS-CoV-2-RNA findings, which could be controversial $(4,28,29,35,36)$. It was recommended that further studies with larger sample sizes and more accurate analyses of patients with reinfection be done to provide better information and documentation of protective cognitive immunity and the vaccine design. Conducting a highvolume sample cohort study was highly important to determine the occurrence of reinfection and to evaluate the signs and symptoms in vitro and molecular forms. Through detecting this evidence, the vaccination program and the method of dealing with it would become much more noticeable for health policymakers, health practitioners, and health care staff. A vaccine should be produced with a very high safety duration to prevent reinfection in patients and people. Also, to produce such a vaccine, the relationship between disease severity and infectivity of the virus should be considered (Table 1).

Moreover, in this review study, clinical and laboratory features were extracted in each episode of COVID-19 based on whether people in the second episode had a mild or moderate form of the disease or a severe form. Thus, the patients in our study were divided into 2 groups according to the second episode: "mild or moderate" and "severe." The results are reported in Tables 2 and 3.

Figure 2 shows the mean duration of first and second episodes as well as the mean interval between the 2 episodes in each group. As summarized in Table 4, the mean durations of the first episode of COVID-19 in the mild or moderate group and the severe group were $24.42 \pm 1.67$ days and $21.80 \pm 3.79$ days, respectively. In this instance, there was no significant difference in the first episode duration between the 2 groups $(p=0.484)$. 
Table 1. The characteristics of included studies

\section{Author and year of Country and type of study}

publication

Gidari A et al. (2020) (45) Italy,

Case report

Kim AY et al. (2020) (27)

USA

Letter to editor

To KK et al. (2020) (22)

China,

Case report

Larson D et al (2020) (10)
USA,

Case report

\section{Main findings of the study}

Averagely, 34.5 days after the initial attack from COVID-19, re-infection occurs in people. $5.6 \%$ of them had fever again and $27.6 \%$ showed other symptoms. $96.7 \%$ of those who have been re-infected had good general health, while $2.1 \%$ died.

ICU admission $=1$

Comorbidity $=3$

Leukopenia $=2$

Normal $\mathrm{WBC}=6$

High $\mathrm{CRP}=0$

IgG+= All patients

PCR in second epi

episode $=$ All Negative

One patient had a significant immune response despite myelodysplastic syndrome an Lymphopenia

Re-infection is possible; so, the necessary training should be given to people and health care providers to give the patients the necessary advice. In patients with re-infection, an appropriate and detailed history should be prepared in order to perform appropriate studies.

Most patients had mild symptoms in the first period and mild or asymptomatic symptoms in the second period of the disease. It is recommended that the concept of re-infection be properly defined. The important point in this study is that selection bias is mentioned that high-risk cases are tested either in clinical or more exposure.

Immunity is gradually lost after COVID-19 in people, but it remains unclear whether reinfection occurs in these people. In this study, genome sequencing analysis of respiratory amples of patients with COVID-19 was performed. PCR, IgG, and IgM results were also performed. The results showed that the second episode of the disease occurred 142 days pertor ter the fir infection netic results showed that the genome affecting the first and second episodes belonged to different genomic groups and lineages, indicating that the genome varied in different ep sodes. Comparison of viral genomes showed that the first episode of the virus genome was phylogenetically closely associated with strains collected in March/April 2020 while the second episode virus genome was closely associated with strains collected in July/Augus 2020. The patient's CRP was 8.8 in the second episode without symptoms. The low titer of neutralizing antibodies in the patient's body can be justified by mild symptoms of the patien and insufficient stimulation of the immune system.

51 days after treating a patient with COVID-19, he returned with COVID-19 symptoms (fever, cough, chills, headache, excessive fatigue, chest pain). He was re-infected. Unlike other studies, re-infection was much more severe than the initial infection, possibly due to strengthening the immune system, obtaining a more pathogenic strain, or perhaps a further inoculation of the infection due to a person's re-exposure to risk factors. The genomes of
The comments of the study

The findings of this study are based on the results of preliminary studies that have identified people with re-infection based on the findings of SARS-CoV-2 RNA, which can be controversial. The results of previous studies have shown that the virus cannot reappear in vitro; so, it cannot reappear in the human body. IgM levels are very high in the first two weeks of the disease, indicating acute existence of antibodies and a history of infection.

Re-infection with coronavirus is very important because the vaccination program and how to deal with it will become much more significant for health policymakers. A vaccine should be produced with a very high safety duration to prevent re-infection in patients and people. In order to produce such a vaccine, the relationship between disease severity and infectivity of the virus should be considered.

Epidemiological, clinical, serological, and genomic analyses confirmed that instead of continuously reducing the virus load after the first episode, the patients are at the risk of re-infection. SARSCoV-2 may contiue CoV-2 may con munity obtained during vaccination or natural infection. Further necessary for protective cognitive immunity and vaccine design.

Conducting a high sample-volume cohort study is very important to determine the occurrence of re-infections and to investigate the symptoms in vitro and molecular form. 
India,

Case report

The results of several studies in the world by examining genome sequencing have shown that re-infection is possible in patients with severe or serious symptoms. Meanwhile, this study showed that re-infection also occurs in asymptomatic patients with COVID-19. The genomes of the virus between two episodes were different and the genetic variant in reinfection was resistant to neutralizing antibodies. Also, the viral load during re-infection was more than that in the first episode. Both cases in this study were hospital staff and had re-exposure.

Van Elslande J et al. (2020) (12)

Belgium, Case report

A 51-year-old woman was infected with COVID-19 in March. After three months (93 days), this person had the symptoms of fever, cough, fatigue, and headache, and COVID-19 re-infection was confirmed by SARS-CoV-2 PCR. Laboratory and molecular assays also showed that the genes of both infections were different. Complete genome sequencing showed that the initial infection was caused by lineage B.1.1 SARS-CoV-2 and recurren infection by lineage A SARS-CoV-2. There were eleven mutations between the genome of the two strains.

Goldman JD et al. (2020)

USA,

Case report

The recovery of COVID-19 is associated with the production of anti-SARS-CoV-2 antibodies, but whether or not this increase in antibodies causes immunity, is still under discussion in the world. Viral RNA decrease rate was checked over time. Out of 818 samples that had positive tests for the first time, 43 were tested positive within 12 to 75 days later. This posit we dis could have differe the nosis may have been done with a CT scan, which is not accurate, and third, the antibody
level has been lowered in re-infected patients.

2 different strains with 10 genetic mutations with an interval of 100 days were isolated from the patient. The neutralizing antibody titer was low despite the high overall $\operatorname{IgG}$ tite and has failed to produce immunity. 11622 patients were tested and 643 had at least on positive test $(5.5 \%)$ and 176 patients had at least 2 positive tests.

Median (interquartile range) shedding duration was $12.1(6.4,24.7)$ days, with a positively skewed distribution (kurtosis $=10.7$ )

Mulder M et al. (2020) (46) Netherland,

Case report

An 89 -year-old female patient was referred in the first episode with symptoms of fever, severe cough, and high lymphocyte count, and its tests were positive. 59 days after this episode, she was referred again with symptoms of advanced fever, severe cough, dyspnea, and positive tests. The results of genome sequencing analysis showed that genetic change and mutation had also occurred in the second episode. Two different strains with 10 genetic mutations were isolated. Immunoglobulin was not formed in her body.

A woman with COVID-19 who had lupus disease 15 years ago was referred. The sympA woman with COVID-19 wo had lupus disease 15 years ago was refered. The symptoms of the fist episode of COVID-19 wro the same as nomal patients with COVID-19. After several weeks' post-recovery, COVID-19 relapsed and the person with more severe symptoms was referred to the hospital. Genetic sequencing has not been performed to compare the virus genome on two occasions of the disease. So, contrary to the author's claims, there is still the possibility of re-infection. The level of $\operatorname{IgG}$ has not been investigated which could have clarified the cause of mildness of the second episode.
In order to confirm these results, further studies and genome analysis for vaccine preparation and immunity of medical staff are needed.

Despite all these studies and genome sequencing analyses, it is not possible to say with $100 \%$ accuracy and reliability that there is a recurring infection. More reviews are needed in this area. But it can be claimed that vaccine production should be difficult considering these gene mutations.

Currently, the issue in the world is the re-infection of COVID-19, but it has not yet been definitely determined. The important point is that all health policymakers, practitioners, and researchers in the field of vaccine production should go hand in hand to further investigate these cases of re-infection. Because some people ma be vestigate these cases of re-infection. Because some people may be seaso infection may challenge all vaccines under production.

Although negative PCR samples have not been reported in this patient between the two episodes, it can be claimed that the second episode is a re-infection rather than a reduction in viral RNA levels.

The patient showed a complete treatment, but this recovery may have been due to the patient's young age. Such patients take different types of medications causing their immune systems to become weakened, which increases the risk of re-infection. Therefore, in the future, it is necessary to conduct a better and more accurate study with higher sample size. 
Table 1.Ct

Author and

publication

Chen D et al. (2020) (16)

Country and type of study

China,

Case report

A $46-\mathrm{y}$

Bonifácio LP et al. (2020)

Brazil,

Case report

Malkov E (2020) (25)

USA,

Modelling

Duggan NM et al. (2020)

(47)

USA,

Case report
A 46-year-old woman was diagnosed 17 days after complete recovering from COVID-19 using the SARS-CoV-2 RNA test of the pharynx. The symptoms of this
second episode were much more severe and different than the first episode.

A 24-year-old woman who was overweight without any underlying disease was referred to the hospital with severe headaches, malaise, weakness, and muscle pain. On the second day, PCR was negative. Because this person had contact with his colleague whose test was positive, so the patient was advised to repeat the tests. On the $7^{\text {th }}$ day, PCR was test was positive, so the patient was advised to repeat the tests. On the 7 day, PCR was
positive. After 14 days of treatment and quarantine period, the patient recovered and positive. After 14 days of treatment and quarantine period, the patient recovered and
returned to work. After two weeks of recovery, she was referred to the hospital again returned to work. After two weeks of recovery, she was referred to the hospital again
with more severe symptoms such as very high fever, malaise, severe weakness, muscle with more severe symptoms such as very high fever, malaise, severe weakness, muscle
pain, and joints. The PCR was positive. Besides, IgG and IgM were negative on the first pain, and joints. The PCR was positive. Besides, IgG and IgM were n
days of the second episode, but they were positive on days 19 and 33 .

This study used a mathematical model to estimate cases of re-infection. The results showed that it is not possible to detect the occurrence of re-infection when the patient is at the peak of infection and disease. On the other hand, controlling and preventive measures can delay the occurrence of re-infection. It is a model based on susceptible, exposed, infected, resistant patients that predict up to $10 \%$ of the population can be reexposed, infected, resistant patients that predict up to $10 \%$ of the population can be re-
infected. If the safety duration after the disease is 60 days and if it remains longer, this infected. If the safety
number will be lower.

number will be lower.
The basis of this model with current re-infection observations is different because the The basis of this model with current re-infection observations is different because the
cases of re-infection before the formation of active and effective immunity (neutralizing antibodies) are re-infected. So, this model is used for post-immune conditions.

An 82-year-old male patient with Parkinson's disease, diabetes, hypertension, and kidney disorders was referred to the hospital. The first primary symptoms were fever and dyspnea. After positive test results and 28 days of hospitalization in ICU. After one week of complete recovery and discharge, the patient with more severe symptoms and high fever, severe shortness of breath, muscle pain was referred to the hospital and CT results indicated the existence of COVID-19. He was treat a indicatization of the patient with Hospitactured duration of readmission is lower than the first time and the response to oxygen therapy is better in the second episode. The positive PCR test is not necessarily a sign of its patho-
genesis in the positive individual.

The comments of the study

Pharyngeal samples should be applied to reduce more falsepositive cases in sampling. It is better for people to be followed up for a certain period after discharge and recovery and to tested again to further investigate the virus activity process. It can be concluded that this instability of symptoms and a positive test after recovery can be explained in three ways:

First, the hypothesis of relapsing the symptom due to a single First, the hypothesis of relapsing the symptom due to a single persistent infection may be theoretically possible, but since this person had contact with the affected family and close people who have been infected, it makes it hard to accept this hypothesis.

Second, the patient might have contact with another respiratory virus, which is similar to the symptoms of COVID-19, and the test might have been a false positive.

Third, it is possible to be a re-infection, which can be almost a strong claim according to the results of other studies. One of the main limitations of this study was the lack of investigation of the virus genome in the first and second episodes. Better and more accurate studies with a higher sample size are recommended.

So far, it has not been determined how long the immunity of the disease disease takes aftr recovery. So, modng and estimating the dises showed that it is possible to be re-infected according to the simulation results. Control practices can somewhat prevent or delay its occurrence.

There is a possibility of re-infection but other infectious diseases such as bacterial pneumonia with symptoms similar to COVID19 should also be considered. The patient in this study was discharged from the hospital after a period of appropriate treatmen with a negative test, but after one week again he was referred with more severe symptoms and it is likely because of other the of with the tests should also be comp 


\section{Author and}

tion

Lafaie L et al. (2020) (23)

Main findings of the study

France,

Case series

Three elderly women with COVID-19 and underlying diseases were studied (hypertension, diabetes, heart disease, and chronic respiratory diseases). In the first episode, the symptoms were milder and the results of CT scan were positive for two of these elderly and negative for one of them, while for a person with a negative CT scan, PCR test was positive. All three patients had complete treatment. Two months later, all three of them were referred to the hospital with more severe clinical symptoms. PCR and CT scan tests were repeated and all were positive. Clinical symptoms were much more severe than the first episode. Although they received the treatment, none of them survived.

Cao $\mathrm{H}$ et al. China,

(2020) (26) Case series

Case report

Gousseff $\mathrm{M}$ et al

(2020) (24)

France,

Case series

Parry J (2020) (5) Hong Kong,

Case report

Bongiovanni M (2020) (20) Italy,

Case report

108 COVID-19 confirmed patients were reviewed, of which 8 (7.5\%) patients had reinfection. In the second admission of these patients, there were no severe symptoms and $\mathrm{CT}$ test results were negative for these patients.

$\mathrm{WBC}=$ Normal

Lymphocyte $=$ Normal

$\mathrm{PCR}=$ Positive

Two patients were discharged, but 6 patients were still hospitalized till the time of writing the article.

A 34-year-old man with COVID-19 and a history of diabetes was discharged from the hospital after two negative PCR tests. After several weeks, his PCR test was positive again. In the second episode, the patient had no symptoms and CT showed the improved bilateral lesions from the first episode. The patient was followed up, and when three PCR tests were negative for him and his bilateral lesions in chest CT were completely absorbed, final discharge was performed.

In this study, 4 of 11 patients were medical staff with a median age of 32.5 (19-43) years, and the remaining 7 patients had a median age of 73 (54-91) years. In the first episode, they had all symptoms such as fever and malaise with weakness; besides, in older people, they had all symptoms such as fever and malaise with weakness; besides, in older people,
these symptoms were more severe. All medical staff did not receive any special treatthese symptoms were more severe. All medical staff did not receive any special treat-
ment, but the elderly had received medications. Averagely, 20 to 30 days after treatment ment, but the elderly had received medications. Averagely, 20 to 30 days after treatment
and withdrawal of symptoms of the first episode, the second episode occurred in these patients.

A 33-year-old man was infected with COVID-19 and referred to the hospital. He was completely treated for 3 weeks. After 4.5 months (135 days), the patient was referred to the hospital again with signs and symptoms of COVID-19 as well as a positive test. The important point was the high load of virus in his body in the second episode. Genetic findings also showed that viruses in the first and second episodes differed in 24 nucleotides that this difference resulted in amino acid alteration in 9 proteins.

A 48-year-old female nurse was referred to the hospital with fever, A 48-year-old fect ale
The comments of the study

It can be said that there is a possibility of recurring infection. So, in the first step, more attention should be paid to the presence of underlying diseases and their role in the occurrence of this infection. In addition, it can be concluded that the disease in the second episode will be much more dangerous and fatal. and cough as well as respiratory symptoms with a positive PCR test in the first episode of the discase. After the treatment peiod and 5 wo negative tests, she was discharged from the hospital and returned to work. After 5 months of discharge and routine work in the hospital, this person was referred to another hospital with symptoms and positive test
Re-infected patients should be the main concern about transmission and the main cause of the outbreak in the community. If the possibility of re-infection is true, the necessary measures should

The results of this study show the importance of follow-up of patients after hospital discharge. These follow-ups can help to better understand the virus and its function in the body or after the treatment.

Re-infection is possible after a certain period of discharge or negative test, which can be caused by decreased power of the immune system or the use of other medications for the treatment of other diseases. The main point about this issue is the health practitioners to be alert, which can help to manage the crisis at the individual and group level. Further studies by evaluating the virus genome can be much more effective.

It can be said that acquired immunity following the first episode of infection only lasted for a short time. When re-infection happens, it can be claimed that the virus has developed genetic mutations over time.

This person has changed her place of work because of her job and has been re-infected due to contact with a companion of a patient with COVID-19. Considering these results, it can be said that there is a possibility of re-infection. be taken as soon as possible for these people. 


\begin{tabular}{|c|c|c|c|c|c|c|c|c|c|c|c|c|}
\hline ID & Patient No. & Age & Sex & Health Condition & First Episode Severity & $\begin{array}{c}\text { Second Episode } \\
\text { Severity }\end{array}$ & $\begin{array}{c}\text { Lymphopenia } \\
\left(1^{\text {st }} / 2^{\text {nd }} \text { episode }\right) \\
\end{array}$ & $\begin{array}{l}1^{\text {st }} \text { episode } \\
\text { CRP } \\
\end{array}$ & $\begin{array}{l}\text { IgG during } \\
2^{\text {nd }} \text { episode } \\
\end{array}$ & $\begin{array}{c}1^{\text {st }} \text { episode } \\
\text { duration } \\
\end{array}$ & $\begin{array}{c}\text { Gap between } \\
\text { episode }\end{array}$ & $\begin{array}{c}2^{\text {nd }} \text { episode } \\
\text { duration }\end{array}$ \\
\hline \multirow{15}{*}{$\begin{array}{l}\text { Gidari A et al. } \\
(2020)\end{array}$} & 1 & 50 & $\mathrm{M}$ & HBV & Severe & Mild & $1 \mathrm{st}$ & - & + & 14 & $20 \mathrm{P}$ & 15 \\
\hline & 2 & 51 & $\mathrm{M}$ & HTN & Mild & Moderate & - & NA & + & 26 & $11 \mathrm{P}$ & 8 \\
\hline & & & & Dyslipidemia & & & & & & & & \\
\hline & & & & Smoker & & & & & & & & \\
\hline & 3 & 45 & $\mathrm{~F}$ & Hypothyroidism & Moderate & Mild & - & NA & + & 17 & $24 \mathrm{P}$ & 6 \\
\hline & 4 & 74 & $\mathrm{M}$ & Healthy & Mild & asymptomatic & - & NA & + & 26 & $15 \mathrm{P}$ & 9 \\
\hline & 5 & 42 & $\mathrm{~F}$ & Healthy & Moderate & Moderate & NA & NA & + & 29 & $27 \mathrm{P}$ & 5 \\
\hline & 6 & 77 & $\mathrm{~F}$ & $\begin{array}{l}\text { Chronic Respiratory disease } \\
\text { Cardiomyopathy }\end{array}$ & Mild & Asymptomatic & - & NA & + & 22 & $42 \mathrm{P}$ & 2 \\
\hline & 7 & 26 & $\mathrm{M}$ & Healthy & Moderate & Asymptomatic & $2^{\text {nd }}$ & NA & - & 16 & $63 \mathrm{P}$ & 4 \\
\hline & 8 & 50 & $\mathrm{M}$ & $\mathrm{DM} 2$ & Severe & Mild & - & - & + & 38 & $60 \mathrm{P}$ & 2 \\
\hline & 9 & 77 & $\mathrm{M}$ & Cardiomyopathy & Mild & Mild & $1^{\text {st }}$ & NA & + & 25 & $30 \mathrm{P}$ & 3 \\
\hline & & & & $\mathrm{AF}$ & & & & & & & & \\
\hline & & & & DM2 & & & & & & & & \\
\hline & & & & Alcoholic Cirrhosis & & & & & & & & \\
\hline & & & & $\begin{array}{l}\text { Myelodysplastic Syndrome } \\
\text { Henatic neoplasm }\end{array}$ & & & & & & & & \\
\hline \multirow{2}{*}{$\begin{array}{l}\text { To KK et al. } \\
(2020)\end{array}$} & 1 & 33 & $\mathrm{M}$ & Healthy & Mild & Asymptomatic & _- & NA & _. & 19 & $123 \mathrm{P}$ & 5 \\
\hline & & & & & & & & & & & & \\
\hline $\begin{array}{l}\text { Larson D et al. } \\
(2020)\end{array}$ & 1 & 42 & $\mathrm{M}$ & Healthy & Mild & Moderate & NA & NA & $+*$ & 10 & $51 \mathrm{C}$ & 14 \\
\hline \multirow{2}{*}{$\begin{array}{l}\text { Gupta V et al. } \\
(2020)\end{array}$} & 1 & 25 & $\mathrm{M}$ & NA & Asymptomatic & Asymptomatic & NA & NA & NA & 8 & $106 \mathrm{P}$ & 14 \\
\hline & 2 & 28 & $\mathrm{~F}$ & $\mathrm{NA}$ & Asymptomatic & Asymptomatic & NA & NA & NA & 10 & $107 \mathrm{P}$ & 6 \\
\hline \multirow{4}{*}{$\begin{array}{l}\text { Van Elslande J et } \\
\text { al. (2020) } \\
\text { Goldman JD et al. } \\
(2020) \\
\text { He F et al. (2020) }\end{array}$} & 1 & 51 & $\mathrm{~F}$ & Asthma & Moderate & Mild & - & NA & + & 35 & $90 \mathrm{C}$ & 10 \\
\hline & 1 & $60-69$ & $\mathrm{NA}$ & Severe Emphysema & Moderate & Moderate & NA & $2^{\text {nd }}$ & + & 41 & $100 \mathrm{P}$ & $>19$ \\
\hline & 1 & & & $\begin{array}{l}\text { HTN } \\
\text { SLE }\end{array}$ & Severe & Mild & - & $1^{\mathrm{st}}$ & NA & 9 & $12 \mathrm{P}$ & 4 \\
\hline & & & & Immunosuppressive drugs & serete & (2) & & & & & $12 \mathrm{P}$ & 4 \\
\hline \multirow{13}{*}{$\begin{array}{l}\text { Bonifácio LP et al. } \\
(2020) \\
\text { Chen D et al. } \\
(2020) \\
\text { Gousseff M et al. } \\
(2020)\end{array}$} & 1 & 24 & F & Overweight & Mild & Mild & - & - & - & 14 & $33 \mathrm{C}$ & 12 \\
\hline & 1 & 46 & $\mathrm{~F}$ & NA & Moderate & Asymptomatic & NA & NA & NA & 14 & $5 \mathrm{P}$ & 3 \\
\hline & 1 & 19 & $\mathrm{~F}$ & None & Moderate & Moderate & NA & NA & + & 18 & $26 \mathrm{C}$ & Ongoing \\
\hline & 2 & 32 & $\mathrm{~F}$ & None & Mild & Mild & NA & NA & NA & 29 & $36 \mathrm{C}$ & 10 \\
\hline & 3 & 33 & $\mathrm{~F}$ & First-trimester pregnancy & Mild & Mild & - & NA & + & 13 & $27 \mathrm{C}$ & 8 \\
\hline & 4 & 43 & M & None & Mild & Mild & - & + & + & 14 & $24 \mathrm{C}$ & 29 \\
\hline & 7 & 91 & F & CHD & Severe & Moderate & & + & + & 13 & $25 \mathrm{C}$ & 9 \\
\hline & & & & HTN & & & $1^{\text {st }}$ & & & & & \\
\hline & & & & CVD & & & & & & & & \\
\hline & & & & Atherosclerosis & & & & & & & & \\
\hline & & & & Arrhythmia & & & & & & & & \\
\hline & 8 & 55 & $\mathrm{M}$ & $\begin{array}{l}\text { DM } \\
\text { CLD }\end{array}$ & Mild & Moderate & $1^{s t} \& 2 n d$ & + & + & 21 & $27 \mathrm{C}$ & 20 \\
\hline & & & & Cirrhosis Child & Horita & Niveriact & & & & & & \\
\hline
\end{tabular}

$8 \quad$ http://mjiri.iums.ac.ir

Med J Islam Repub Iran. 2021 (1 Nov); 35:144. 


\begin{tabular}{|c|c|c|c|c|c|c|c|c|c|c|c|c|}
\hline ID & $\begin{array}{l}\text { Patient } \\
\text { No. }\end{array}$ & Age & Sex & Health Condition & First Episode Severity & $\begin{array}{l}\text { Second Episode } \\
\text { Severity }\end{array}$ & $\begin{array}{c}\text { Lymphopenia } \\
\left(1^{\text {st }} / 2^{\text {nd }} \text { episode }\right)\end{array}$ & $\begin{array}{l}1^{\text {st }} \text { episode } \\
\text { CRP }\end{array}$ & $\begin{array}{l}\text { IgG during } \\
2^{\text {nd }} \text { episode }\end{array}$ & $\begin{array}{l}1^{\text {st }} \text { episode } \\
\text { duration }\end{array}$ & $\begin{array}{l}\text { Gap be- } \\
\text { tween } \\
\text { episode }\end{array}$ & $\begin{array}{c}2^{\text {nd }} \text { episode } \\
\text { duration }\end{array}$ \\
\hline $\begin{array}{l}\text { Bongiovanni M } \\
\text { (2020) }\end{array}$ & 1 & 48 & NA & - & Mild & Asymptomatic & $\mathrm{NA}$ & NA & NA & 22 & NA & NA \\
\hline $\begin{array}{l}\text { Parry J } \\
(2020)\end{array}$ & 1 & 33 & $\mathrm{M}$ & NA & Mild & Asymptomatic & NA & NA & NA & 21 & NA & 145 \\
\hline \multirow{8}{*}{ Cao H et al. (2020) } & 1 & 54 & $\mathrm{~F}$ & - & Severe & Asymptomatic & - & NA & + & 36 & $13 \mathrm{P}$ & NA \\
\hline & 2 & 72 & $\mathrm{~F}$ & - & Moderate & Asymptomatic & 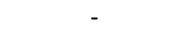 & NA & + & 18 & $13 \mathrm{P}$ & NA \\
\hline & 3 & 60 & $\mathrm{~F}$ & - & Moderate & Asymptomatic & - & NA & + & 30 & $10 \mathrm{P}$ & NA \\
\hline & 4 & 65 & $\mathrm{~F}$ & Hypothyroidism & Moderate & Asymptomatic & - & NA & + & 36 & $13 \mathrm{P}$ & NA \\
\hline & 5 & 58 & M & Tuberculosis & Moderate & Asymptomatic & - & NA & + & 31 & $17 \mathrm{P}$ & $\mathrm{NA}$ \\
\hline & 6 & 64 & $\mathrm{M}$ & - & Severe & Asymptomatic & - & NA & + & 6 & $27 \mathrm{P}$ & NA \\
\hline & 7 & 36 & $\mathrm{~F}$ & - & Moderate & Asymptomatic & - & NA & + & 30 & $7 \mathrm{P}$ & NA \\
\hline & 8 & 26 & M & - & Moderate & Asymptomatic &  & NA & + & 19 & $7 \mathrm{P}$ & NA \\
\hline $\begin{array}{l}\text { Dou } C \text { et al. } \\
(2020)\end{array}$ & 1 & 34 & M & DM2 & Severe & Asymptomatic & & + & & 22 & $18 \mathrm{P}$ & 22 \\
\hline
\end{tabular}

^: Either reported according as Clinical relief to $2^{\text {nd }}$ positive PCR shown by "C" / negative PCR to $2^{\text {nd }}$ positive PCR shown by "P"

AF: Atrial Fibrillation, ATC: Anti Coagulation Therapy, CHD: Congenital Heart Disease, CKD: Chronic Kidney Disease, CLD: Chronic Lung Disease, COPD: Chronic Obstructive Pulmonary Disease, CRD: Chronic Renal Disease, CVD: Cerebrovascular

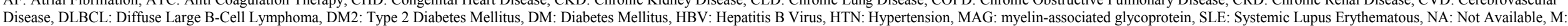

Male, F: Female. 


\begin{tabular}{|c|c|c|c|c|c|c|c|c|c|c|c|c|}
\hline ID & $\begin{array}{l}\text { Patient } \\
\text { No. }\end{array}$ & Age & Sex & Health Condition & $\begin{array}{c}\text { First Episode } \\
\text { Severity }\end{array}$ & $\begin{array}{r}\text { Second Epi- } \\
\text { sode Severity }\end{array}$ & $\begin{array}{c}\text { Lymphopenia } \\
\left(1^{\text {st }} / 2^{\text {nd }} \text { episode }\right)\end{array}$ & $\begin{array}{l}1^{\text {st }} \text { episode } \\
\text { CRP }\end{array}$ & $\begin{array}{l}\text { IgG during } \\
2^{\text {nd }} \text { episode }\end{array}$ & $\begin{array}{l}1^{\text {st }} \text { episode } \\
\text { duration }\end{array}$ & $\begin{array}{c}\text { Gap between } \\
\text { episode }^{\wedge}\end{array}$ & $\begin{array}{c}2^{\text {nd }} \text { episode } \\
\text { duration }\end{array}$ \\
\hline $\begin{array}{l}\text { Mulder M et } \\
\text { al. } \\
(2020)\end{array}$ & 1 & 89 & $\mathrm{~F}$ & $\begin{array}{l}\text { Waldenstrom macroglobu- } \\
\text { linemi (B-cell immunocom- } \\
\text { promised) }\end{array}$ & Mild & $\begin{array}{c}\text { Severe } \\
\text { Expired }\end{array}$ & & $1^{\mathrm{st}}$ & - & 5 & $54 \mathrm{C}$ & $\begin{array}{c}22 \\
\text { Expired }\end{array}$ \\
\hline $\begin{array}{l}\text { Duggan NM et } \\
\text { al. } \\
(2020)\end{array}$ & 1 & 82 & $\mathrm{M}$ & $\begin{array}{c}\text { HTN } \\
\text { DM } \\
\text { CKD } \\
\text { Parkinson's Disease }\end{array}$ & Severe & Severe & NA & NA & NA & 39 & $10 \mathrm{C}$ & 12 \\
\hline \multirow[t]{5}{*}{$\begin{array}{c}\text { Gousseff } M \text { et } \\
\text { al. } \\
(2020)\end{array}$} & 5 & 85 & M & $\begin{array}{c}\text { Bronchiectasis } \\
\text { CHD } \\
\text { Pacemaker } \\
\text { Arrhythmia }\end{array}$ & Severe & Severe & $1^{\text {st }} \& 2 \mathrm{nd}$ & + & NA & 17 & $44 \mathrm{C}$ & 6 \\
\hline & 6 & 54 & M & HTN & Severe & $\begin{array}{l}\text { Severe } \\
\text { Expired }\end{array}$ & $1^{\text {st }} \& 2$ nd & + & + & 41 & $45 \mathrm{C}$ & 34 Expired \\
\hline & 9 & 72 & $\mathrm{M}$ & $\begin{array}{l}\text { Anti MAG neuropathy (ritux- } \\
\text { imab, bendamustine) }\end{array}$ & Severe & $\begin{array}{l}\text { Severe } \\
\text { Expired }\end{array}$ & $1^{\text {st }} \& 2$ nd & + & - & 21 & $27 \mathrm{C}$ & 29 Expired \\
\hline & 10 & $\begin{array}{l}73 \\
84\end{array}$ & $\begin{array}{c}\mathrm{M} \\
\mathrm{F}\end{array}$ & DLBCL (chemotherapy d-22) & $\begin{array}{l}\text { Mild } \\
\text { Severe }\end{array}$ & $\begin{array}{l}\text { Severe } \\
\text { Severe }\end{array}$ & $\begin{array}{l}1^{\text {st }} \& 2 \mathrm{nd} \\
1^{\text {st }} \& 2 \mathrm{nd}\end{array}$ & + & - & $\begin{array}{l}13 \\
23\end{array}$ & $\begin{array}{c}24 \mathrm{C} \\
49\end{array}$ & $\begin{array}{l}17 \\
30\end{array}$ \\
\hline & & & & $\begin{array}{c}\text { Mild CRD } \\
\text { CHD } \\
\text { Arrhythmia/ATC Valvulopa- } \\
\text { thy } \\
\text { Atherosclerosis } \\
\text { DM }\end{array}$ & & & & & & & & \\
\hline \multirow[t]{3}{*}{$\begin{array}{l}\text { Lafaie L et al. } \\
\quad(2020)\end{array}$} & 1 & 84 & $\mathrm{~F}$ & $\begin{array}{c}\text { HTN } \\
\text { Heart disease } \\
\text { Cancer } \\
\text { COPD }\end{array}$ & Severe & $\begin{array}{l}\text { Severe } \\
\text { Expired }\end{array}$ & $1^{\text {st }} \& 2$ nd & + & - & 15 & $\begin{array}{l}\text { More than one } \\
\text { month C }\end{array}$ & 14 Expired \\
\hline & 2 & 90 & $\mathrm{~F}$ & $\begin{array}{l}\text { HTN } \\
\text { DM2 }\end{array}$ & Severe & $\begin{array}{l}\text { Severe } \\
\text { Expired }\end{array}$ & $2 \mathrm{nd}$ & + & NA & 32 & $4 \mathrm{C}$ & 9 Expired \\
\hline & 3 & 84 & $\mathrm{~F}$ & $\begin{array}{c}\text { Heart disease } \\
\text { HTN } \\
\text { Heart disease } \\
\text { Immunosuppression }\end{array}$ & Severe & $\begin{array}{l}\text { Severe } \\
\text { Expired }\end{array}$ & $1^{\text {st }} \& 2 \mathrm{nd}$ & + & + & 12 & 10 & 19 Expired \\
\hline
\end{tabular}

^: Either reported according as Clinical relief to $2^{\text {nd }}$ positive PCR shown by "C" / negative PCR to $2^{\text {nd }}$ positive PCR shown by "P"

*: Patient was tested 14 days after symptoms onset of the second episode

AF: Atrial Fibrillation, ATC: Anti Coagulation Therapy, CHD: Congenital Heart Disease, CKD: Chronic Kidney Disease, CLD: Chronic Lung Disease, COPD: Chronic Obstructive Pulmonary Disease, CRD: Chronic Renal Disease, CVD: Cerebrovascular Disease, DLBCL: Diffuse Large B-Cell Lymphoma, DM2: Type 2 Diabetes Mellitus, DM: Diabetes Mellitus, HBV: Hepatitis B Virus, HTN: Hypertension, MAG: myelin-associated glycoprotein, NA: Not Available, SLE: Systemic Lupus Erythematous 


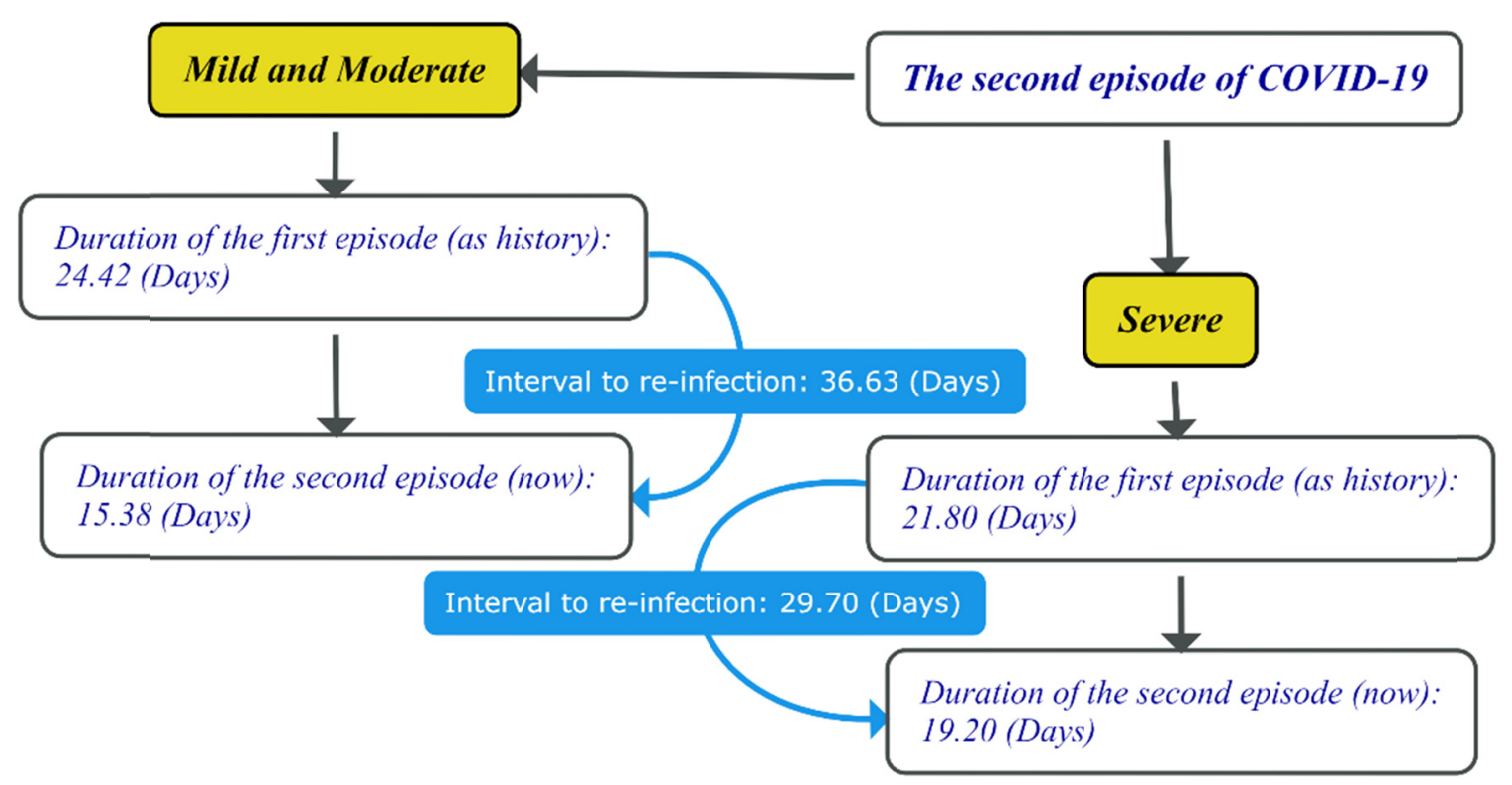

Fig. 2. A schematic diagram of the main finding of our study

Besides, the mean durations of reinfection in the mild or moderate group and the severe group were $15.38 \pm 5.57$ days and $19.20 \pm 2.98$ days, respectively; however, these durations did not significantly differ between the 2 groups $(\mathrm{p}=0.675)$. The interval duration between the 2 episodes in the mild or moderate group was $36.63 \pm 5.71$ days, which was significantly longer than this interval in the severe group $(29.70 \pm 5.65$ days $)(\mathrm{p}<0.001)$ (Table 4$)$.

Following the assessment of the cases above, this theory could be suggested that, in general, reinfected patients were divided into 2 categories:

1. Healthy people with the mild or moderate disease in the first episode

2. High-risk people with the severe form of the disease in the first episode

In the first category, reinfection occurred because of the lack of effective specific immunity (neutralizing antibody) at a longer interval with the primary infection and possibly as a result of contact with a new strain. There was a possibility of an immune cross-reactivity resulted from other coronaviruses, which made B-cells naive not to be reactivated specifically for COVID-19. Therefore, people who had experienced the disease mildly without any immune response, despite the high level of $\mathrm{IgG}$, did not have neutralization of function to clean the virus and were reinfected with new strains.

In the second category, the second episode was more severe because of the inability to provide an immune response at a shorter interval, being in a high-risk situation (because of long hospitalization in care centers and the need for more services and consequently more contacts), and having lower cardiorespiratory capacity. Inflammation caused the disease not to be diagnosed in patients with underlying diseases, which made the hospitalization process more difficult, leading to increased mortality. As a result, in these patients, if reinfection occurred in a short time and immunity was not formed, the body would not tolerate second stress and mortality would increase. Therefore, the follow-up of cured patients who were critically ill by COVID-19 through PCR is of high importance, and this population should be prioritized for vaccination.

\section{Discussion}

The number of confirmed COVID-19 cases and its correlated mortality and morbidity has been increasing so fast since its first report in December 2019. As we all know, COVID-19 is caused by Coronavirus 2 (SARS-CoV-2) $(37,38)$. It was believed that C.OVID-19 was an infectious disease whose incidence in the elderly as well as in patients with chronic diseases, such as cardiovascular disease, respiratory disease, renal disease, et cetera, was higher than that in healthy individuals $(39,40)$. Immunocompromised individuals were at higher risk of pulmonary

Table 4. The comparison of mean episode duration between mild or moderate and sever COVID-19

\begin{tabular}{|c|c|c|c|c|}
\hline Episodes & COVID-19 Groups & Mean and SE & Mean Difference & P Value $(\% 95 \mathrm{CI})$ \\
\hline \multirow[t]{2}{*}{ First Episode } & Mild or Moderate & $24.42 \pm 1.67$ & 2.62 & $0.484(-4.88$ to \\
\hline & Severe & $21.80 \pm 3.79$ & & 10.14) \\
\hline \multirow{3}{*}{ Second Episode } & Mild or Moderate & $15.38 \pm 5.57$ & -3.84 & $0.675(-22.31$ to \\
\hline & Severe & $19.20 \pm 2.98$ & & 24.69) \\
\hline & COVID-19 Groups & Mean and SE & Mean Difference & P Value $(\% 95 \mathrm{CI})$ \\
\hline \multirow[t]{2}{*}{ Gap between two episodes } & Mild or Moderate & $36.63 \pm 5.71$ & 6.913 & 0.0001 \\
\hline & Severe & $29.70 \pm 5.65$ & & \\
\hline
\end{tabular}


or extrapulmonary complications during respiratory infections (41). However, recently, one of the major concerns about COVID-19 was an increasing rate of reinfection in all age groups, which in some cases could be presented with more severe symptoms, rapidly leading to death.

Many cases of SARS-CoV-2 infection in recurrent periods had been described in case reports, and there was not any vast evaluation, such as cohort studies, in this field. The present systematic review was aimed to describe the current scientific evidence on COVID-19 in reinfected patients as well as the mortality and morbidity risk of recurrence in these individuals.

The results were investigative of an infection recurrence episode in different time intervals from 4 to 123 days. They reported that most of the patients were treated after reinfection and the exact rate of mortality and morbidity was still unknown $(21,22,30,42)$. Regardless of mortality and morbidity of reinfection (of course if we considered it low), it was very important for the vaccination plan. Consequently, the coronavirus vaccine should have a longer immune duration. In order to produce such a vaccine, it was necessary to consider the relation of disease severity as well as its pathogenesis (43). The immunity after the first infection disappeared after a short time. One of the major signs of reinfection was $\mathrm{IgG}$ and $\mathrm{C}$-reactive protein (CRP) rise (43). IgM levels sharply raised in the first 2 weeks of illness, indicating an acute infection, and after 1 week, $\mathrm{IgG}$ levels raised, indicating the presence of antibodies and a history of infection. Then, IgG levels decreased slowly (21). Therefore, it could be concluded that IgG level measurement might be an appropriate guide for diagnosing reinfection.

To KK et al reported that the phylogenic strains of the virus in the first and second episodes were very simillar to the collected strains in March/April 2020 and August 2020, respectively (22). Some scientists believed that the second episode of infection could be more severe than the first. It could be more likely due to the strengthening of the immune system, the acquisition of more pathogenic strains, or perhaps an inoculation of the infection because of exposure of a patient to the risk factors $(6,10,16)$. In some cases, the patients could be asymptomatic (31). In symptomatic patients, the symptoms were similar to those of the first episode (fever, cough, headache, malaise, chest pain, etc.) (10). The mild and asymptomatic cases had usually more ribonucleic acid (RNA) loss than severe cases. For confirming the reinfection, PCR could not be a good method because it could be positive for almost 100 days. Thus, in these cases, complete genome sequencing or viral culture was needed (12). The results of genetic tests and study of the whole genome showed that in the first episode, mutations occurred in 5 types of genes, and in the second episode, mutations occurred with more numbers in more genes. The SNYs were the same in both samples, but the loci were different and more numerous in the type of re-infection (6). The other important finding was the genetic mutation which could have occurred in the second episode of infection (14).

Another study used mathematical modeling for estimating the reinfection cases. The results demonstrated that it was not possible to diagnose reinfection when the patient was at the peak of infection and disease. On the other hand, control and preventive attempts could delay the occurrence of reinfection (25). There was the likelihood of being another simultaneous infectious disease with COVID-19, such as bacterial pneumonia, which had similar signs and symptoms of COVID-19 (16). Chronic diseases could be important factors of mortality and morbidity in reinfection. In patients with chronic disease, reinfection appeared with more severe signs and symptoms, which may lead to death easier $(16,18)$.

Reinfection and recurrence in the body after a certain period from discharge or negative tests in individuals were possible, which could be because of the decreased power of the immune system or use of other drugs to treat further diseases. The key was the vigilance of health professionals and health policymakers on this issue, which could help to manage the epidemic at the individual and group levels. Performing more studies and assessing the virus genome could be much more effective (44). One of the important points about reinfection was that the virus load was much higher in the second episode. Genetic findings also showed that the number of nucleotides involved in the first and second episodes may differ so much in terms of protein amino acid cleavage (25).

\section{Study Limitation}

Given that in most cases, in the second episode of the disease, the person had severe symptoms, leading to death, we cannot claim with certainty about the duration of the second episode of the disease, and the say that the length of the second episode in severe cases are shorter than in mild or moderate cases may be slightly different from reality.

\section{Conclusion}

All practitioners and health providers should be very careful about the severity of the second episode because of the more need for medical interventions for saving the patients. The interval between the first end and the second episode as well as the duration of each episode is very important to have better management. Moreover, it is important to conduct a high sample size cohort study to determine the incidence of reinfections and evaluate the signs and symptoms in terms of laboratory and molecular assessments because if there is such evidence, the vaccination schedule and the way of dealing with it for health policymakers, health professionals, and health care staff will become more significant. The vaccine should have very long immunogenicity to prevent reinfection in patients and members of the community. To produce such a vaccine, the relationship between disease severity and virus pathogenicity must be considered.

\section{Conflict of Interests}

The authors declare that they have no competing interests. 


\section{References}

1. Sohrabi C, Alsafi Z, O’Neill N, Khan M, Kerwan A, Al-Jabir A, et al. World Health Organization declares global emergency: A review of the 2019 novel coronavirus (COVID-19). Int J Surg. 2020.

2. Organization WH. Coronavirus disease 2019 (COVID-19): situation report, 47. 2020.

3. Seah I, Agrawal R. Can the coronavirus disease 2019 (COVID-19) affect the eyes? A review of coronaviruses and ocular implications in humans and animals. Ocul Immunol Inflamm. 2020;28(3):391-5.

4. Malkov E. Simulation of coronavirus disease 2019 (COVID-19) scenarios with possibility of reinfection. Chaos Solitons Fractals. 2020;139:110296.

5. Parry J. Covid-19: Hong Kong scientists report first confirmed case of reinfection. British Medical Journal Publishing Group; 2020.

6. Tillett R, Sevinsky J, Hartley P, Kerwin H, Crawford N, Gorzalski A, et al. Genomic evidence for a case of reinfection with SARS-CoV-2. Available at SSRN 3680955. 2020.

7. Khangura S, Konnyu K, Cushman R, Grimshaw J, Moher D. Evidence summaries: the evolution of a rapid review approach. Syst Rev. 2012;1(1):10.

8. Tricco AC, Antony J, Zarin W, Strifler L, Ghassemi M, Ivory J, et al. A scoping review of rapid review methods. BMC Med. 2015;13(1):224.

9. Moher D, Stewart L, Shekelle P. All in the family: systematic reviews, rapid reviews, scoping reviews, realist reviews, and more. BioMed Central. 2015.

10. Larson D, Brodniak SL, Voegtly LJ, Cer RZ, Glang LA, Malagon FJ, et al. A Case of Early Re-infection with SARS-CoV-2. Clin Infect Dis. 2020.

11. Gupta VK, Waugh CA, Ziklo N, Huston WM, Hocking JS, Timms P. Systemic antibody response to Chlamydia Trachomatis infection in patients either infected or reinfected with different Chlamydia serovars. Indian J Med Microbiol. 2017;35(3):394-401.

12. Van Elslande J, Vermeersch P, Vandervoort K, Wawina-Bokalanga T, Vanmechelen B, Wollants E, et al. Symptomatic SARS-CoV-2 reinfection by a phylogenetically distinct strain. Clin Infect Dis. 2020.

13. Goldman JD, Wang K, Roltgen K, Nielsen SCA, Roach JC, Naccache SN, et al. Reinfection with SARS-CoV-2 and Failure of Humoral Immunity: a case report. medRxiv: the preprint server for health sciences. 2020.

14. Mulder M, Oude BM, GeurtsvanKessel C, Sikkema R, Jacobs E, Koopmans $\mathrm{M}$, et al. Reinfection of SARS-CoV-2 in an immunocompromised patient: a case report. Clin Infect Dis. 2020.

15. He FQ, Sauermann U, Beer C, Winkelmann S, Yu Z, Sopper S, et al. Identification of molecular sub-networks associated with cell survival in a chronically SIVmac-infected human CD4+ T cell line. Virol J. 2014;11:152.

16. Chen D, Xu W, Lei Z, Huang Z, Liu J, Gao Z, et al. Recurrence of positive SARS-CoV-2 RNA in COVID-19: A case report. Int J Infect Dis. 2020.

17. Bonifácio LP, Pereira APS, Balbão VdMP, Fonseca BALd, Passos ADC, Bellissimo-Rodrigues F. Are SARS-CoV-2 reinfection and Covid-19 recurrence possible? a case report from Brazil. Rev Soc Bras Med. 2020;53.

18. Duggan NM, Ludy SM, Shannon BC, Reisner AT, Wilcox SR. Is novel coronavirus 2019 reinfection possible? Interpreting dynamic SARS-CoV-2 test results through a case report. Am J Emerg Med. 2020

19. Dou C, Xie X, Peng Z, Tang H, Jiang Z, Zhong Z, et al. A case presentation for positive SARS-CoV-2 RNA recurrence in a patient with a history of type 2 diabetes that had recovered from severe COVID-19. Diabetes Res Clin Pract. 2020;166:108300.

20. Bongiovanni M. COVID-19 re-infection in an healthcare worker. J Med Virol. 2021;33(10):11.

21. Gidari A, Nofri M, Saccarelli L, Bastianelli S, Sabbatini S, Bozza S, et al. Is recurrence possible in coronavirus disease 2019 (COVID-19)? Case series and systematic review of literature. Eur J Clin Microbiol. Infect. Dis. 2020:1-12.

22. To KK, Hung IF, Ip JD, Chu AW, Chan WM, Tam AR, et al. COVID-19 re-infection by a phylogenetically distinct SARScoronavirus- 2 strain confirmed by whole genome sequencing. Clin Infect Dis. 2020.

23. Lafaie L, Célarier T, Goethals L, Pozzetto B, Grange S, Ojardias E, et al. Recurrence or relapse of COVID-19 in older patients: a description of three cases. J Am Geriatr Soc. 2020.

24. Gousseff M, Penot P, Gallay L, Batisse D, Benech N, Bouiller K, et al. Clinical recurrences of COVID-19 symptoms after recovery: viral relapse, reinfection or inflammatory rebound? J Infect. 2020.

25. Malkov E. Simulation of coronavirus disease 2019 (COVID-19) scenarios with possibility of reinfection. Chaos Solitons Fractals. 2020:110296.

26. Cao H, Ruan L, Liu J, Liao W. The clinical characteristic of eight patients of COVID-19 with positive RT-PCR test after discharge. J Med Virol. 2020.

27. Kim AY, Gandhi RT. Re-infection with SARS-CoV-2: What Goes Around May Come Back Around. Clinical infectious diseases: an official publication of the Infectious Diseases Society of America. 2020.

28. To KKW, Hung IFN, Ip JD, Chu AWH, Chan WM, Tam AR, et al. COVID-19 re-infection by a phylogenetically distinct SARScoronavirus- 2 strain confirmed by whole genome sequencing. Clin Infect Dis. 2020.

29. To KKW, Hung IFN, Ip JD, Chu AWH, Chan WM, Tam AR, et al. Coronavirus disease 2019 (COVID-19) re-infection by a phylogenetically distinct severe acute respiratory syndrome coronavirus 2 strain confirmed by whole genome sequencing. Clin Infect Dis. 2020.

30. To KK, Hung IF, Chan KH, Yuan S, To WK, Tsang DN, et al. Serum antibody profile of a patient with COVID-19 reinfection. Clin Infect Dis. 2020.

31. Gupta V, Bhoyar RC, Jain A, Srivastava S, Upadhayay R, Imran M, et al. Asymptomatic reinfection in two healthcare workers from India with genetically distinct SARS-CoV'-2. Clin Infect Dis. 2020.

32. Bongiovanni M. COVID-19 re-infection in an healthcare worker. J Med Virol. 2020.

33. Bongiovanni M, Basile F. Re-infection by COVID-19: a real threat for the future management of pandemia? Infect Dis (London, England). 2020;52(8):581-2.

34. He F, Luo Q, Lei M, Fan L, Shao X, Hu K, et al. Successful recovery of recurrence of positive SARS-CoV-2 RNA in COVID-19 patient with systemic lupus erythematosus: a case report and review. Clin Rheumatol. 2020:1-8.

35. Chen J, Lu H, Melino G, Boccia S, Piacentini M, Ricciardi W, et al. COVID-19 infection: the China and Italy perspectives. Cell Death Dis. 2020;11(6):1-17.

36. Lee JT, Hesse EM, Paulin HN, Datta D, Katz LS, Talwar A, et al. Clinical and Laboratory Findings in Patients with Potential SARSCoV-2 Reinfection, May-July 2020.. Clin Infect Dis. 2021.

37. Huang MA, Lok AS. Natural history of hepatitis B and outcomes after liver transplantation. Clin Liver Dis. 2003;7(3):521-36.

38. Huang WY. [Survival of the third stage larvae of anisakis simplex in various conditions and experimental infection in rats]. Zhongguo Ji Sheng Chong Xue Yu Ji Sheng Chong Bing Za Zhi. 2005;23(2):106-9.

39. Lipsitch M, Swerdlow DL, Finelli L. Defining the epidemiology of Covid-19—-studies needed. N Engl J Med. 2020;382(13):1194-6.

40. Qiu L, Liu X, Xiao M, Xie J, Cao W, Liu Z, et al. SARS-CoV-2 is not detectable in the vaginal fluid of women with severe COVID-19 infection. Clin Infect Dis. 2020.

41. José RJ, Dickey BF, Brown JS. Infectious respiratory disease in nonHIV immunocompromised patients. Br J Hosp Med. 2014;75(12):68590 .

42. Gousseff M, Penot P, Gallay L, Batisse D, Benech N, Bouiller K, et al. Clinical recurrences of COVID-19 symptoms after recovery: viral relapse, reinfection or inflammatory rebound? $\mathrm{J}$ Infect. 2020;81(5):816-46.

43. Kim AY, Gandhi RT. Re-infection with SARS-CoV-2: what goes around may come back around. Clin Infect Dis. 2020.

44. York A. Can COVID-19 strike twice? Nat Rev Microbiol. 2020.

45. Gidari A, Nofri M, Saccarelli L, Bastianelli S, Sabbatini S, Bozza S, et al. Is recurrence possible in coronavirus disease 2019 (COVID-19)? Case series and systematic review of literature. Eur J Clin Microbiol Infect Dis. 2020.

46. Mulder M, van der Vegt D, Oude Munnink BB, GeurtsvanKessel $\mathrm{CH}$, van de Bovenkamp J, Sikkema RS, et al. Reinfection of SARSCoV-2 in an immunocompromised patient: a case report. Clin Infect Dis. 2020.

47. Duggan NM, Ludy SM, Shannon BC, Reisner AT, Wilcox SR. Is novel coronavirus 2019 reinfection possible? Interpreting dynamic SARS-CoV-2 test results through a case report. Am J Emerg Med. 2020. 